\title{
La teoria de la sensibilidad en la estética de Gilles Deleuze y su articulación con la filosofía trascendental
}

(1) Pablo Nicolás Pachilla

Consejo Nacional de Investigaciones Científicas y Técnicas-Universidad de Buenos Aires, Argentina.

Dirección: tesis en co-tutela. Por la Universidad de Buenos Aires: Dr. Marcelo Raffin (director), Dr. Edgardo Gutiérrez (codirector); por la Univeristé Paris 8: Dr. Patrick Vauday (director). Jurado: por la parte argentina: Dr. Julián Ferreyra, Dr. Emmanuel Biset y Dr. Marcelo Raffin; por la parte francesa: Dra. Anne Sauvagnargues (presidenta del jurado), Dr. Frédéric Rambeau y Dr. Patrick Vauday. Fecha de defensa: 27 de febrero de 2018.

La tesis en cuestión se ocupa de la transición, los puntos de contacto y de ruptura entre las filosofías de Immanuel Kant y de Gilles Deleuze y, más precisamente, entre el idealismo trascendental creado por el primero y el empirismo trascendental propuesto por el último. En el transcurso del trabajo se señalan y determinan pues una serie de problemas relativos a la relación entre la filosofía deleuziana y la filosofía kantiana. En la primera parte, "Deleuze leyendo a Kant" (Capítulos 1 y 2), se releva con detenimiento la lectura deleuziana del filósofo de Königsberg tal como aparece en La Philosophie critique de Kant (1963), en la cual encontramos que el concepto de sentido común aparece como la base fundante del sistema crítico. En el Capítulo 1, nos detenemos en la interpretación deleuzianade la Crítica de la razón pura presente en aquel libro. En contraste con una visión aséptica de la razón, se enfatiza allí su vínculo con el deseo a partir de la noción de interés de la razón, así como la concepción jurídica en el marco de la cual Kant concibe derechos naturales de la razón conducentes a la legitimidad de algunas de sus pretensiones y la ilegitimidad de otras-de allí la utilización por nuestra parte del término "iusnaturalismo noético". Analizamos asimismo el argumento deleuziano según el cual la armonía preestablecida leibniziana sobreviviría en el sistema crítico kantiano bajo la forma de una adecuación entre facultades radicalmente heterogéneas, i.e. entendimiento y sensibilidad. En vista de ello, prolongamos la línea interpretativa de Deleuze de acuerdo con la cual el idealismo trascendental encuentra su fundamento en el postulado de un sensus communis, apuntando las implicancias teológicas y teleológicas del mismo.
De las concordancias sujetas, legisladas y presididas entre las facultades presentes en las dos primeras Críticas, pasamos en el Capítulo 2 a las concordancias no-legisladas presentes en la Crítica de la facultad de juzgar. Puesto que allí emergía a la superficie la cuestión del sentido común subyacente a las dos Críticas previas, la tercera Crítica kantiana se revelaba no como un complemento sino como una fundamentación de las anteriores. Encontrábamos en ella una tentativa de responder por adelantado a la exigencia genética del poskantismo; era preciso que el acuerdo entre las facultades fuese engendrado en el desacuerdo, y de este modo, dimos con tres requisitos exigidos por Deleuze: discordancia, contingencia y vivificación de la concordancia entre las facultades. No podíamos estar de acuerdo con Deleuze, empero, en que dichos requisitos se encontraran satisfechos en Kant, siempre que lo que parecía animar las facultades por la discordancia de un encuentro contingente era en el fondo una astucia de la Naturaleza suprasensible para favorecer su realización en la naturaleza sensible a través del hombre. La relación entre las facultades, aún en su momento de máxima tensión, estaba contenida por el principio de conformidad a fin (Zweckmäßigkeit), que las ajustaba entre ellas y las adecuaba en su relación con el mundo.

En la segunda parte, "Kant en Deleuze", nos abocamos a las reapropiaciones, reelaboraciones y contraposiciones de Deleuze con respecto a la filosofía kantiana. En el Capítulo 3, desplegamos las distintas notas del concepto de sentido común, tomando como base el tercer capítulo de Diferencia y repetición, "La imagen del pensamiento". En primer lugar, se examina la relación entre el concepto kantiano de sentido común y el concepto deleuziano de imagen del pensamiento, focalizando particularmente los postulados de la naturaleza recta del pensamiento y del error como su negativo, así como la relación entre los conceptos deleuzianos de sentido común y buen sentido, con las determinaciones temporales y espaciales impuestas por este último con respecto al carácter nomádico del sentido. Yendo a obras deleuzianas posteriores - Mil mesetas (1980), co-escrita junto a Félix Guattari, así como La imagen-tiempo (1985)—, analizamos también el aspecto político del sentido común y su relación con el lugar común; vimos, allí, que el sentido común era un sentido comunitario (en Kant, "gemeinschaftlicher Sinn") relativo al consenso y a las pretensiones de la representación. En segundo lugar, desarrollamos en el Capítulo 4 una serie de herramientas para romper 
con el sentido común y el sistema de la representación, tal como eran tomadas por Deleuze del propio Kant, y observamos algunas transformaciones en este pasaje: de lo sublime como afinación para la moralidad ("Analítica de lo sublime") al encuentro con la intensidad en la sensibilidad, que forzaba un movimiento en el alma y hacía nacer al pensamiento (tercer capítulo de Diferencia y repetición); de la paradoja del sentido interno (\$24 de la Crítica de la razón pura) a la fisura del yo (segundo capítulo de Diferencia y repetición, "La repetición para sí misma") y el cogito esquizofrénico (Mil mesetas); del orden formal del tiempo ("Estética trascendental") a la cesura que abría el porvenir como eterno retorno y esparcía los fragmentos del yo fracturado, creando algo nuevo en el proceso (tercera síntesis del tiempo en Diferencia y repetición).

En la tercera parte, "Kant más allá de Kant", adoptamos el punto de vista de la génesis propuesto por Deleuze. En el Capítulo 5, analizamos en este sentido las influencias del poskantismo y del neokantismo en el empirismo trascendental de Diferencia y repetición. Vimos cómo el concepto de intensidad, forjado por Kant en las "Anticipaciones de la percepción", era reapropiado por Deleuze a partir de la lectura de Hermann Cohen (Kants Theorie der Erfahrung). Ello le servía para invertir la relación entre lo extensivo y lo intensivo, y pensar un spatium intensivo irreductible y previo a las coordenadas extensivas. Asimismo, esto resultaba indispensable para combatir la ilusión trascendental de la entropía y la anulación de la diferencia estipulada por el buen sentido del tiempo. Por otra parte, examinamos la noción de Idea tal como era tomada por Deleuze de la filosofía trascendental, tanto en el aspecto problemático de las mismas delineado por el propio Kant como en su determinación recíproca y diferencial propuesta por Salomon Maimon (Versuchüber die Transzendentalphilosophie). El estatuto pre-conceptual y pre-sensible de estos problemas virtuales hacía posible su actualización en espacio-tiempos, a través de los dinamismos que Deleuze pensó, inspirándose en el esquematismo kantiano, como una dramatización.

En el Capítulo 6, por último, abordamos la cuestión del arte, problematizando la sugerencia deleuziana de unificación de las dos estéticas kantianas (estética trascendental y teoría de gusto) y comprobando sus ambigüedades. Esta problematización implicó necesariamente una revisión de las síntesis pasivas temporales conceptualizadas por Deleuze en el segundo capítulo de Diferencia y repetición. La temporalidad se reveló, en efecto, como el factor decisivo a la hora de pensar tanto la estética como la creación en general, y de allí que el examen de la tercera síntesis del tiempo en el Capítulo 4 nos haya servido para pensar el proceso de creación pictórica-tomando como punto de partida Francis Bacon. Lógica de la sensación (1981) y las clases de Deleuze del mismo año. Vimos, asimismo, que la transición, exigida por Deleuze, desde las condiciones de la experiencia posible a las condiciones de la experiencia real requería de un descentramiento serial y un perspectivismo ontológico posibilitado por el abandono de la condición de concordancia; esto, sin embargo, debía ser logrado a través de un conjunto de procedimientos, que Deleuze encontraba en la literatura llamada "moderna". Esbozamos una concepción de la estética deleuziana como una conceptualización de varias aristas, donde emergían tanto una estética de lo sublime desde el punto de vista del espectador como una lógica de la sensación desde el punto de vista del creador y una meta-estética filosófica como creación de conceptos adecuados a perceptos y afectos-esta última, tematizada en tanto tal recién en ¿Qué es la filosofía? (1991).

Otro problema que surgía en relación a la razón en su interés especulativo en Kant era el de los juicios de percepción, esto es, la posibilidad de una experiencia sin objeto. Sostenemos que este problema acaso irresoluble en el plano filológico de los estudios kantianos alberga sin embargo un potencial para pensar otro concepto de experiencia. Si el término "experiencia" debía limitarse al conocimiento objetivo, ello es prueba suficiente de que el plano trascendental propuesto por la primera Crítica kantiana no era condición de posibilidad de toda la experiencia, dado que hay, como Kant mismo lo vio, experiencia no objetiva. El atolladero aparecía en cuanto Kant no podía pensar esta otra experiencia sino como subjetiva o intersubjetiva. En cambio, si tomamos la concepción deleuziana del campo trascendental como no objetivo ni subjetivo, la experiencia sin objeto puede adquirir otro tipo de consistencia. En el último texto publicado por Deleuze — “La inmanencia: una vida..."-, se lee que el campo trascendental "se presenta como pura corriente de conciencia a-subjetiva, conciencia pre-reflexiva impersonal, duración cualitativa de la conciencia sin yo". Esta corriente de conciencia, en efecto, puede pensarse como la presentación de multiplicidades previa a toda representación de lo múltiple en tanto que subordinado a lo uno.

Deleuze propone una ontología en la que lo real consiste de flujos. Podemos pensar entonces las facultades como flujos (de la sensibilidad, de la memoria, del pensamiento). Los flujos vibran a una determinada frecuencia, y por eso pueden estar afinados o desafinados con respecto a un determinado fin. Un fin supone lo que Deleuze denomina una síntesis conjuntiva entre los flujos, tal que ellos concuerden entre sí y que quede por fuera de la síntesis aquello que no se presta a ser 
concordante. Esto es para Deleuze el sentido común. Su propuesta es la de una determinada relación entre los flujos que no esté sujeta a la condición de la concordancia (síntesis disyuntiva). El empirismo trascendental consiste en la búsqueda de las presentaciones de la diferencia no sujetas a dicha condición, y en la experimentación proclive a la producción de nuevos órdenes de diferencia. 